University of Wollongong

Research Online

Australian Institute for Innovative Materials -

Papers

Australian Institute for Innovative Materials

$1-1-2016$

The study of deposition of wood extractives and model compound colloids onto chromium and cellulose surfaces using quartz crystal microbalance with dissipation (QCM-D)

Yuen Y. Tham

University of Tasmania

Paul J. Molino

University of Wollongong, pmolino@uow.edu.au

Michael J. Higgins

University of Wollongong, mhiggins@uow.edu.au

Karen R. Stack

University of Tasmania

Desmond E. Richardson

Norske Skog Papermills Australia Ltd

See next page for additional authors

Follow this and additional works at: https://ro.uow.edu.au/aiimpapers

Part of the Engineering Commons, and the Physical Sciences and Mathematics Commons

Research Online is the open access institutional repository for the University of Wollongong. For further information contact the UOW Library: research-pubs@uow.edu.au 


\title{
The study of deposition of wood extractives and model compound colloids onto chromium and cellulose surfaces using quartz crystal microbalance with dissipation (QCM-D)
}

\begin{abstract}
Quartz crystal microbalance with dissipation monitoring (QCM-D) was used to investigate the fundamental interactions between wood extractives and surfaces used in papermaking. Experiments were carried out at $25 .{ }^{\circ} \mathrm{C}$ and $50 .{ }^{\circ} \mathrm{C}$ on a microcrystalline cellulose-coated surface (a surrogate for paper) and a chromium surface (a surrogate for metal surfaces in paper machines and printing presses) using colloids prepared from wood extractives and model compounds of the components in wood extractives. Differences in adsorption behaviour were observed between the two surfaces as a function of temperature. On both surfaces, triolein and abietic acid were found to deposit to a greater extent than wood extractives, mixed model compounds and oleic acid. At $25 .{ }^{\circ} \mathrm{C}$ the colloids were found to have two phases of adsorption onto cellulose surfaces, an initial rapid adsorption phase followed by a slower phase, compared to a single adsorption phase onto chromium. At $50 .{ }^{\circ} \mathrm{C}$, only a single adsorption phase was observed on both surfaces. Abietic acid and oleic acid were found to desorb readily from both the cellulose and chromium substrates, while triolein remained strongly adsorbed. However significantly more abietic acid remained on the chromium surface at $25 .{ }^{\circ} \mathrm{C}$ compared to any other tested material, providing a possible explanation for the observed high rates of resin acid deposition onto metal surfaces during papermaking and printing. At $25 .{ }^{\circ} \mathrm{C}$ and $50 .{ }^{\circ} \mathrm{C}$, less wood extractives and mixed model compound colloids were deposited onto cellulose than onto chromium, which may also explain the high rates of deposition on the metal surface. Stabilisation of the colloids due to interactions between different components within the colloid results in lower deposition of wood extractives and mixed model compound colloids compared to individual component colloids.

Disciplines

Engineering | Physical Sciences and Mathematics

\section{Publication Details}

Tham, Y. Yue., Molino, P. J., Higgins, M. J., Stack, K. R., Richardson, D. E. \& Lewis, T. (2016). The study of deposition of wood extractives and model compound colloids onto chromium and cellulose surfaces using quartz crystal microbalance with dissipation (QCM-D). Colloids and Surfaces A: Physicochemical and Engineering Aspects, 491 1-11.
\end{abstract}

\section{Authors}

Yuen Y. Tham, Paul J. Molino, Michael J. Higgins, Karen R. Stack, Desmond E. Richardson, and Trevor W. Lewis 


\section{The Study of Deposition of Wood Extractives and Model Compound Colloids onto Chromium and Cellulose Surfaces using Quartz Crystal Microbalance with Dissipation (QCM-D)}

Yuen Yue Tham¹, Paul J. Molino², Michael J. Higgins², Karen R. Stack¹, Desmond E. Richardson ${ }^{3}$, Trevor W. Lewis $^{1}$

Affiliations

1 University of Tasmania, School of Physical Sciences (Chem), Hobart, Tas 7001, Australia. ${ }^{2}$ University of Wollongong, ARC Centre of Excellence Electromaterials Science, Intelligent Polymer Research Institute, AllM Facility, Wollongong, NSW, Australia. ${ }^{3}$ Norske Skog Paper Mills Australia Ltd, Boyer, Tas 7140, Australia.

Corresponding author: Address: Locked Bag 1371, Launceston, Tas, Australia, 7250. Ph (61) 036324 3826. Fax (61) 036324 3839. Email: Yuen.Tham@utas.edu.au or Trevor.Lewis@utas.edu.au 


\begin{abstract}
Quartz crystal microbalance with dissipation monitoring (QCM-D) was used to investigate the fundamental interactions between wood extractives and surfaces used in papermaking. Experiments were carried out at $25^{\circ} \mathrm{C}$ and $50^{\circ} \mathrm{C}$ on a microcrystalline cellulose-coated surface (a surrogate for paper) and a chromium surface (a surrogate for metal surfaces in paper machines and printing presses) using colloids prepared from wood extractives and model compounds of the components in wood extractives. Differences in adsorption behaviour were observed between the two surfaces as a function of temperature. On both surfaces, triolein and abietic acid were found to deposit to a greater extent than wood extractives, mixed model compounds and oleic acid. At $25^{\circ} \mathrm{C}$ the colloids were found to have two phases of adsorption onto cellulose surfaces, an initial rapid adsorption phase followed by a slower phase, compared to a single adsorption phase onto chromium. At $50^{\circ} \mathrm{C}$, only a single adsorption phase was observed on both surfaces. Abietic acid and oleic acid were found to desorb readily from both the cellulose and chromium substrates, while triolein remained strongly adsorbed. However significantly more abietic acid remained on the chromium surface at $25^{\circ} \mathrm{C}$ compared to any other tested material, providing a possible explanation for the observed high rates of resin acid deposition onto metal surfaces during papermaking and printing. At $25^{\circ} \mathrm{C}$ and $50^{\circ} \mathrm{C}$, less wood extractives and mixed model compound colloids were deposited onto cellulose than onto chromium, which may also explain the high rates of deposition on the metal surface. Stabilisation of the colloids due to interactions between different components within the colloid results in lower deposition of wood extractives and mixed model compound colloids compared to individual component colloids.
\end{abstract}

Keywords: quartz crystal microbalance with dissipation, wood extractive, cellulose, chromium, temperature, oleic acid, abietic acid, triolein, deposition 


\section{Introduction}

Dissolved and colloidal substances (about 2-4\% of the dry weight of wood) are released into process water during the production of thermo mechanical pulp (TMP) from the softwood Pinus radiata. ${ }^{1}$ The colloidal component consists of fatty and resin acids, triglycerides and sterols, which are referred to collectively as wood extractives..$^{1-5}$ At the typical pH of paper mill process water ( pH 5-6), wood extractives disperse in the water phase as colloidal droplets, adopting a layered structure with steryl esters and triglycerides at the core of the droplet, while the fatty acids and resin acids form the outer layer. ${ }^{4}$ Destabilization and aggregation of these extractives lead to problems such as the formation of deposits onto surfaces of paper machines during the paper making process. ${ }^{6}$ They may also have a detrimental effect if released into the environment. ${ }^{7}$

As a means of reducing the amount of wood extractives in process water, they may be incorporated into paper by the use of a range of retention chemicals without compromising the paper strength. 7,8 While successful at removing wood extractives from the process water, this in turn can generate a new set of problems. For example, wood extractives may desorb from the paper onto surfaces that the paper subsequently contacts such as chromiumcoated rollers in printing presses (Richardson D, pers. comm.). As a result, films of deposits have been observed on papermaking machinery and printing presses where dried paper contacts solid surfaces in an air environment. It has also been observed that by far the major component of these deposits is resin acids (Richardson D, pers. comm.). There is a clear need to understand why only resin acids desorb from the paper, while other components such as fatty acids and triglycerides are retained within the paper web.

Techniques such as photometric dispersion analysis (PDA), , 10 impinging jet microscopy, ${ }^{11}$ surface plasmon resonance (SPR), ${ }^{12}$ flow cytometry ${ }^{13,14}$ and laser diffraction, ${ }^{13,}{ }^{15}$ have been used to characterize and understand the underlying processes governing wood extractives colloidal stability and, thus, the deposition of colloidal wood extractives onto surfaces. Quartz crystal microbalance with dissipation (QCM-D) is a highly sensitive surface sensing technique used extensively as a mass detector for in-situ detection and monitoring of interfacial phenomena in vacuum, ambient and aqueous environments ${ }^{16,17}$ (for review, see Marx ${ }^{18}$ ). The QCM technique was originally pioneered by Sauerbrey ${ }^{19}$, who first described the mass sensing capability of quartz crystals. Initial application of QCM focused on the measurement of the adsorbed mass of chemical species to the QCM sensor surface in gas phase $\mathrm{e}^{20}$, however the technique was soon developed to operate in liquids, where new systems in such diverse areas as electrochemistry 21,22 , immunology ${ }^{23}$ and even cell biology ${ }^{24,25}$ were investigated. In addition to measurement of the mass adsorbed to the sensor surface (i.e. frequency), a second measurement parameter, the dissipation factor $(D)$, was soon developed that provided information regarding the mechanical, or viscoelastic properties of the adsorbed layer. ${ }^{26-28}$ The most modern QCM systems provide measurement of both frequency and dissipation measurement parameters that can be applied to viscoelastic models used to describe adsorbed layer properties including areal mass, thickness and shear modulus. 
QCM has previously been employed to investigate the adsorption of wood extractives to varying surfaces. ${ }^{29-31}$ Tammelin et al. have used QCM-D to create model surfaces (cellulose, lignin and wood extractives surfaces) as well as to study the effect of dissolved hemicellulose on adsorption of colloidal extractives onto these model surfaces when conditions varied (mainly peroxide bleaching or varying ionic strength). ${ }^{29} \mathrm{QCM}-\mathrm{D}$ was also used to study the adsorption mechanism of fatty acids ${ }^{30}$ as well as sodium oleate adsorption to a hydroxyapatite surface ${ }^{31}$. In this contribution, however, QCM-D was used to study the effect of adsorption and desorption of colloidal wood extractives and the individual model compounds onto a model surfaces (cellulose and chromium surfaces) with changing temperature. The adsorption dynamics of each component was studied in real-time, and their affinity for each model substrate determined.

\section{Materials and Methods}

The quartz crystal microbalance with dissipation (QCM-D) instrument used was a Q-sense $E 4$ (Q-sense $A B$, Västra Frölunda, Sweden). $6 \mathrm{mM} \mathrm{NaCl}$ solution was used as the aqueous background electrolyte in all solution preparation as well as in each rinsing process for QCM-D adsorption experiments.

\section{$2.1 \quad$ Model surfaces}

\subsubsection{QCM-D Sensor Preparation}

The QCM-D crystals were A-T cut quartz crystals with a $10 \mathrm{~mm}$ diameter gold (QSX301) or $15 \mathrm{~mm}$ diameter chromium (QSX315) electrode surface with a fundamental resonance frequency of $5 \mathrm{MHz}$ (Q-Sense AB). Prior to each experiment, the quartz crystal surface was cleaned with Piranha solution $(70 \%$ sulphuric acid and $30 \%$ hydrogen peroxide) for 3 minutes, rinsed with deionized water and dried under a stream of nitrogen gas. The crystals were then UV-cleaned for 10 minutes in a Bioforce Nanosciences UV/Ozone Procleaner ${ }^{\mathrm{TM}}$, rinsed with 70\% ethanol and dried under a stream of nitrogen gas. Chromium-coated QCM-D sensors were then directly used in adsorption experiments, while gold-coated sensors were subsequently modified with microcrystalline cellulose prior to the measurement of colloidal adsorption to the sensor surface.

\subsubsection{Cellulose Modification of QCM-D Sensors}

Microcrystalline cellulose-coated quartz crystals were prepared in-situ in the QCM-D flow cells using gold-coated quartz crystal sensors. Sensors were first modified with poly(ethylene) imine (PEI) in-situ in the QCM-D flow cell by passing a $5 \mathrm{mg} \mathrm{mL}^{-1} \mathrm{PEI}$ ( $25000 \mathrm{MW}$, Aldrich) solution through the cell for 15 minutes at $40 \mu \mathrm{L} \mathrm{min}^{-1}$. After rinsing with deionised water for 30 minutes at $40 \mu \mathrm{L} \mathrm{min}^{-1}$, a microcrystalline cellulose suspension was introduced into the flow cell for 2 hours at $40 \mu \mathrm{L} \mathrm{min}-1$. The microcrystalline cellulose suspension was prepared by sonicating a $5 \%$ w/w solution of microcrystalline cellulose (Serva-Avicel PH 105, ca. $0.019 \mathrm{~mm}$ ) in deionised water for 12 minutes. The microcrystalline cellulose suspension was then filtered through a $0.22 \mu \mathrm{m}$ filter to ensure a uniform dispersion of microcrystalline cellulose particles to the flow chambers. The filtrate was used for the subsequent modification of the PEI coated QCM-D sensor. After 2 hours of incubation in the microcrystalline cellulose 
suspension the QCM-D chamber was rinsed with $6 \mathrm{mM} \mathrm{NaCl}(\mathrm{aq})$ until the QCM-D parameters (frequency and dissipation) stabilized, at which time the sensors were ready for subsequent colloidal adsorption experiments.

\subsubsection{Microcrystalline cellulose-coated glass slides}

Glass cover slips (ProSciTech, Coverglass No. 1, $18 \mathrm{~mm}$ ) were sputter-coated with $4 \mathrm{~nm}$ titanium followed by 30 $\mathrm{nm}$ gold. The gold-coated glass cover slips were then placed into a $5 \mathrm{mg} \mathrm{mL}^{-1} \mathrm{PEI}$ solution in deionised water on an orbital stirrer for 15 minutes. Microcrystalline cellulose mixture suspension was prepared as described above. The PEl-coated cover slips were then thoroughly rinsed with deionised water, and placed into the microcrystalline cellulose suspension on an orbital stirrer for 2 hours. Thereafter the cover slips were gently rinsed with deionised water and left to air-dry. These glass slides were used for characterisation purposes only (that is atomic force microscopy imaging and contact angle measurements only).

\subsection{Characterisation of Model Surfaces}

\subsubsection{Atomic Force Microscopy (AFM)}

AFM images were obtained in tapping mode in air using a $\mu$ Mash NSCI5 cantilever (spring constant $40 \mathrm{~N} / \mathrm{m}$ ) fitted to a MFP-3D atomic force microscope (Asylum Research). Three AFM images (at $1 \mu \mathrm{m} \times 1 \mu \mathrm{m}$ resolution) were taken per sample for each model surface and the mean surface roughness measurement ( $R_{\text {RMs }}$ roughness) obtained.

\subsubsection{Contact Angle Measurement - Goniometry}

A Dataphysics Contact Angle System in conjunction with SCA20 software was used to calculate the contact angle of a $1 \mu \mathrm{L}$ sessile drop (MilliQ water, $18 \mathrm{M} \Omega$ ) on the film surfaces. Contact angle measurements were run in triplicate for three samples of each surface.

\subsection{QCM-D Investigation of Wood Extractive - Surface Interactions}

\subsubsection{Adsorbed materials}

Colloidal wood extractives: Wood extractives (WE) were extracted from TMP according to the method described

by Stack et al. ${ }^{32}$ Aqueous dispersions of wood extractives were prepared by dissolving approximately $0.0200 \mathrm{~g}$ of extracted wood extractives in $<1 \mathrm{~mL}$ of acetone, followed by dispersion of acetone-extractives solution into a stirred $20 \mathrm{~mL}$ aqueous $6 \mathrm{mM} \mathrm{NaCl}$ solution to provide stable colloidal dispersions of the wood extractives.

Colloidal model compounds: Colloidal dispersions of model compounds (oleic acid (OA), abietic acid (AA) or triolein (TrO)) were individually made following the method for colloidal wood extractives. An additional aqueous dispersion of a mixture of all the three model compounds (MM) was also prepared following the above method. Figure 1 illustrates the chemical structure of the model compounds investigated. The concentration of each colloidal 
solution, determined by gas chromatography, is given in Table 1. Measurements were undertaken in triplicate and results averaged.
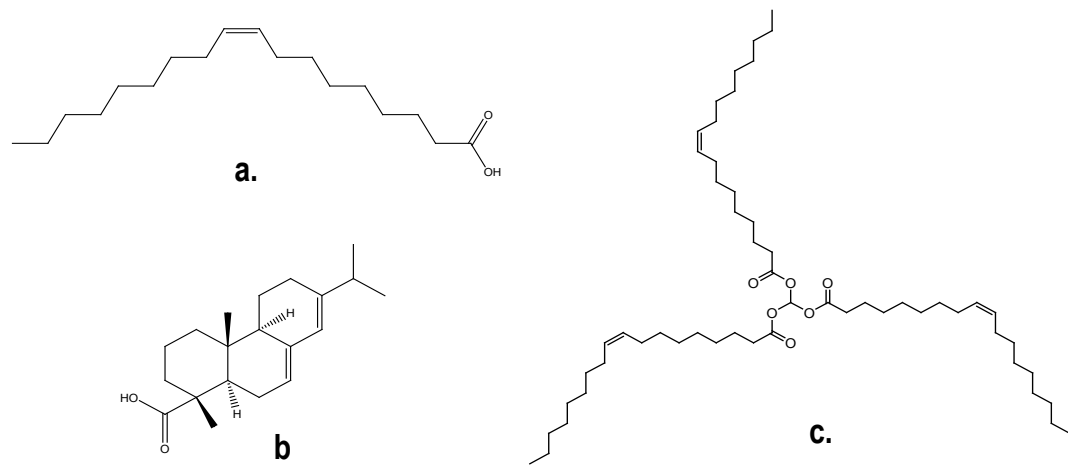

Figure 1 Chemical structures of model compounds representative of the components in wood extractives. (a) oleic acid (OA), representative of fatty acids; (b) abietic acid (AA), representative of resin acids; (c) triolein (TrO), representative of triglycerides.

Table 1 Mean concentration (and standard deviation) $\left(\mathrm{mg} \mathrm{L}^{-1}\right)$ of colloidal material at the commencement of the experiment. The concentration of each individual component is listed for wood extractives and mixed model colloidal material.

\begin{tabular}{|l|c|c|}
\hline \multirow{2}{*}{ Colloid } & \multicolumn{2}{|c|}{ Concentration (mg L-1) } \\
\cline { 2 - 3 } & Mean & Standard Deviation \\
\hline Wood extractives (WE) & & \\
Fatty Acids & 11 & 0.5 \\
Resin Acids & 190 & 16.1 \\
Triglycerides & 245 & 13.5 \\
Total & 446 & \\
\hline Mixed Model (MM) & & \\
Oleic Acid & 196 & 75.2 \\
Abietic Acid & 34 & 12.0 \\
Triolein & 221 & 94.8 \\
Total & 451 & \\
\hline Oleic Acid (OA) & 217 & 18.3 \\
\hline Abietic Acid (AA) & 86 & 6.2 \\
\hline Triolein (TrO) & 407 & 68.7 \\
\hline
\end{tabular}

These concentrations of colloidal materials were chosen to ensure there was an excess of colloidal material always passing through the QCM-D flow chambers, in order to minimise the loss of material to other surfaces before reaching the sensor surface. 


\subsubsection{QCM-D adsorption experiments}

Adsorption experiments of colloidal model compounds and wood extractives onto microcrystalline cellulosemodified and chromium surfaces were carried out at $25^{\circ} \mathrm{C}$ and $50^{\circ} \mathrm{C}$. Temperature $\left(25^{\circ} \mathrm{C}\right.$ and $\left.50^{\circ} \mathrm{C}\right)$ was electronically controlled and maintained by the QCM-D instrument. The $\mathrm{pH}$ of the colloidal solutions was measured at the start and end of the experiments to ensure that the $\mathrm{pH}$ did not change. The $\mathrm{pH}$ of $\mathrm{OA}, \mathrm{TrO}, \mathrm{MM}$ and WE colloidal solutions was $\sim 5$, whereas the $\mathrm{pH}$ of the AA colloidal solution was at $\sim 4$. The frequency and dissipation measurement parameters of the QCM-D crystals were allowed to stabilize in a $6 \mathrm{mM} \mathrm{NaCl}$ (aqueous background electrolyte solution) at the relevant temperature prior to the adsorption experiments. Colloidal materials were then introduced into the flow chamber at $20 \mu \mathrm{L} \mathrm{min}{ }^{-1}$ for 2 hours before rinsing with $6 \mathrm{mM} \mathrm{NaCl}$ for at least 4 hours. QCM-D measurement parameters were recorded during rinsing in order to quantify desorption of the adsorbed colloidal material during this time. All QCM-D experiments were run in triplicate to check repeatability of adsorption measurements.

Frequency and dissipation measurements from the $5^{\text {th }}, 7^{\text {th }}$ and $9^{\text {th }}$ overtones were used for viscoelastic modelling in order to estimate the adsorbed mass to the sensor surface. The Voigt model has previously been used to characterise the adsorption of fatty acids, including oleic acid 30,31 using QCM-D and therefore we have employed the Voigt representation here using the following modelling parameters (fluid density and viscosity of $1000 \mathrm{~kg} \mathrm{~m}^{-3}$ and $0.001 \mathrm{~kg} \mathrm{~m}^{-1} \mathrm{~s}^{-1}$, respectively, layer density of $1150 \mathrm{~kg}^{-1} \mathrm{~m}^{-3}$, layer viscosity of $1^{-6} \leq 1^{-2} \mathrm{~kg} \mathrm{~kg}^{-1} \mathrm{~ms}^{-1}$, shear modulus of $1^{4} \leq 1^{8} \mathrm{~Pa}$ and mass of $\left.115 \leq 1.15^{5} \mathrm{ng}^{-1} \mathrm{~cm}^{-2}\right)$.

\section{Results}

\subsection{Characterisation of model surfaces}

AFM images of the microcrystalline cellulose-modified surface showed nodule-like structures ${ }^{33}\left(R_{\text {RMS }}\right.$ roughness $=$ $0.80 \pm 0.10 \mathrm{~nm}$ ), whereas commercial chromium-coated sensor crystals appeared more homogenous with no features greater than $5 \mathrm{~nm}$ in height ( $R_{\text {RMS }}$ roughness $=0.92 \pm 0.08 \mathrm{~nm}$ ) (Figure 2). RRMS roughness of gold QCMD sensor is $3.44 \pm 0.10 \mathrm{~nm}$. Contact angle measurements on gold, microcrystalline cellulose and chromium surfaces indicate that the microcrystalline cellulose-modified surface is more hydrophilic than gold surface, although the chromium surface was the most hydrophilic interface of all three materials (Table 2). Contact angle measurements (Table 2) illustrate a clear difference in contact angle measurements between PEI-coated and PEImicrocrystalline cellulose coated surfaces. 

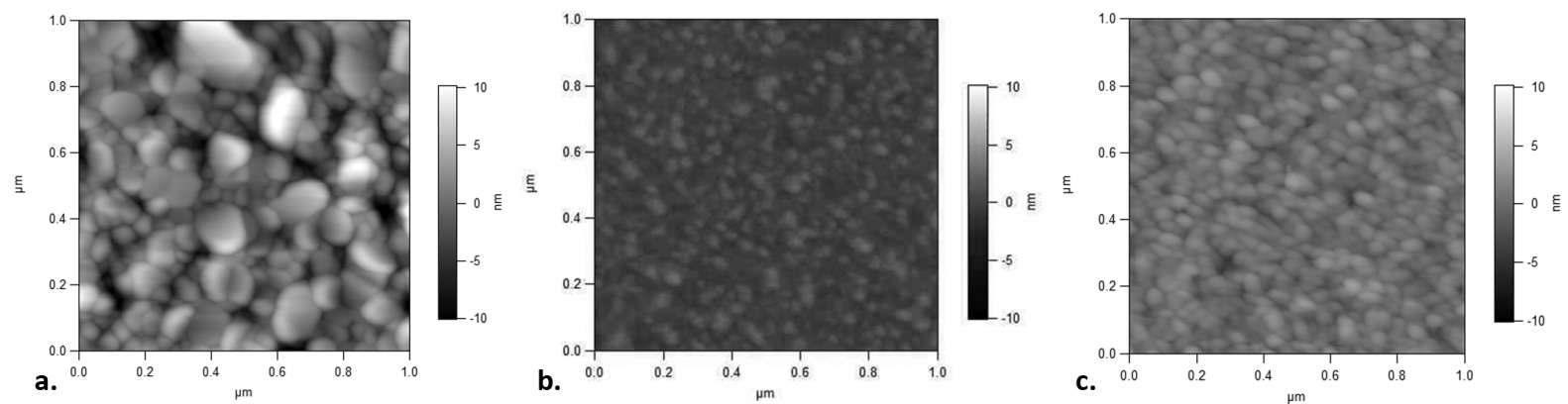

Figure 2 AFM surface topography images of gold QCM-D sensor (a), PEI-microcrystalline cellulose modified glass cover slip (b), and a chromium coated QCM-D sensor (c). All images obtained in AC mode. Dimensions $1.0 \mu \mathrm{m} \times 1.0 \mu \mathrm{m}$.

Table 2 Mean experimental contact angle of each model surface compared with literature contact angle (except that of PEI).

\begin{tabular}{|l|c|c|c|c|}
\hline \multirow{2}{*}{ Model Surfaces } & \multicolumn{2}{|c|}{ Experimental Contact Angle $\left(^{\circ}\right)$} & \multicolumn{2}{c|}{ Literature Contact Angle $\left(^{\circ}\right)$} \\
\cline { 2 - 5 } & Angle & SD & Angle & SD \\
\hline Gold & 96.0 & 1.5 & $\leq 70^{34}$ & - \\
\hline Microcrystalline Cellulose & 61.7 & 8.5 & $64.3^{35}$ & 1.1 \\
\hline Chromium & 48.8 & 2.6 & $20-60^{36}, 70^{37}$ & - \\
\hline PEI & 74.1 & 9.1 & - & - \\
\hline
\end{tabular}

\subsection{QCM Adsorption experiments}

An example of typical changes to QCM-D frequency and dissipation values during the in-situ surface modification stages and adsorption and desorption of wood extractive onto the cellulose surface (on QCM-D sensor surface) is presented in Figure 3. This graph clearly shows that both PEI and microcrystalline cellulose adsorb to the sensor surface effectively, with the QCM-D measurement parameters reaching equilibrium during the rinsing process, presenting a stable interface under the experimental conditions. 


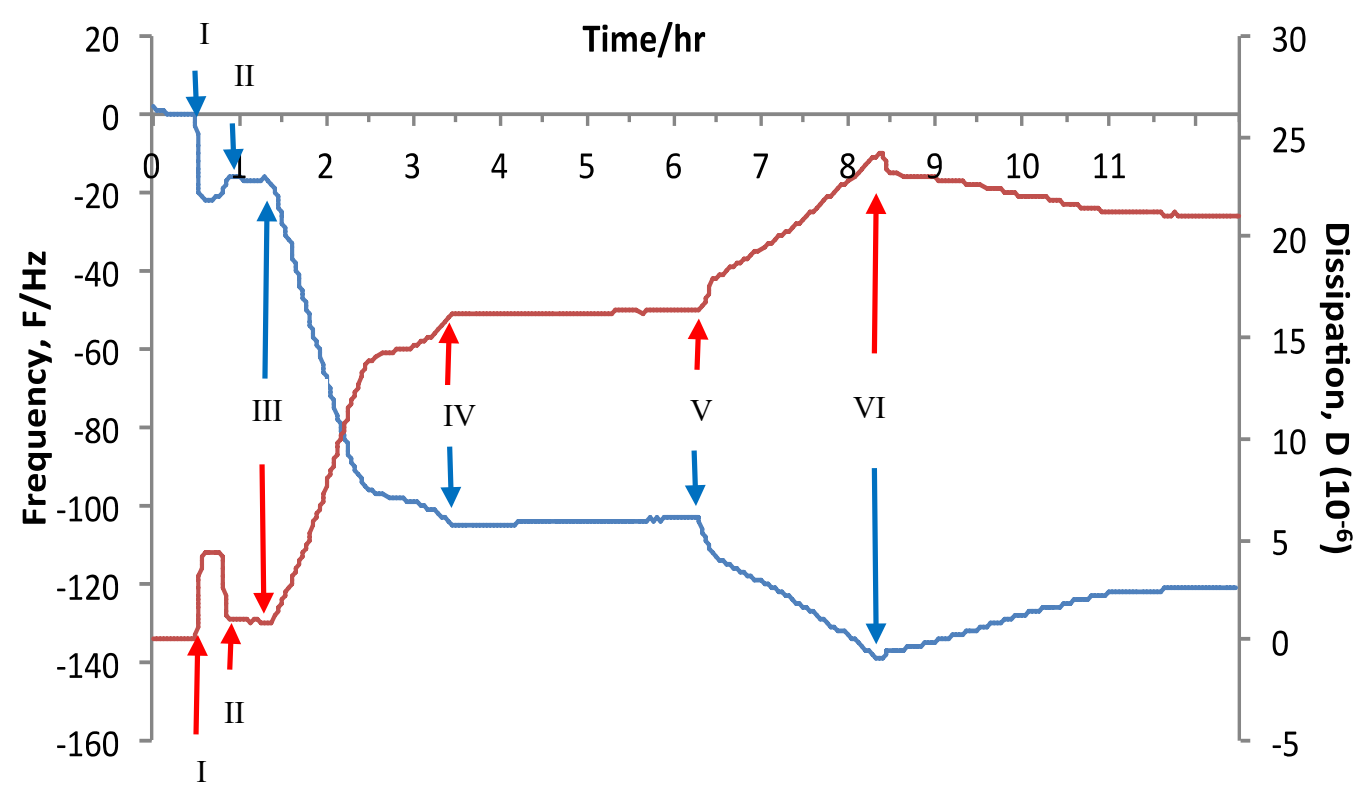

Figure 3 An example of the changes in frequency (blue line) and dissipation (red line) for adsorption of wood extractive onto cellulose surface at $25^{\circ} \mathrm{C}$ as different modifications and solutions are introduced into the QCM-D flow chambers. Background solution was passed through the sensor chamber until a baseline achieved. (I) Then PEI solution were passed through the sensor chamber for 20-25 min. In all experiments, saturation of PEI on sensor surface was achieved quickly. (II) Rinsing with background solution were carried out to remove any excess PEI solution. (III) Filtered microcrystalline cellulose suspension was introduced into the flow chambers for 2 hours. (IV) Rinsing with background solution commenced to remove any excess microcrystalline cellulose suspension until the QCM-D parameters stabilized, thus providing a stable film on the QCM sensor surface. (V) Wood extractive colloidal solution introduced into flow chamber for 2 hours. (VI) Rinsing with background solution carried out for 4 hours.

Typical plots of the mass deposited onto cellulose and chromium surfaces at $25^{\circ} \mathrm{C}$ and $50^{\circ} \mathrm{C}$ as a function of time for the different colloidal materials are shown in Figures 4 and 5 . In the case of the cellulose surface (Figure 4), at $25^{\circ} \mathrm{C}$ the adsorption of all colloidal types, except oleic acid, illustrate an initial rapid adsorption phase followed by a slower secondary adsorption phase that continued until rinsing of the flow cell commenced at $2 \mathrm{hr}$. At $50^{\circ} \mathrm{C}$, adsorption onto the cellulose surface exhibited only a single phase for all colloidal materials, except for the mixed model compounds (MM).

In the case of deposition onto a chromium surface (Figure 5) there was only a single adsorption phase for all colloidal materials at both $25^{\circ} \mathrm{C}$ and $50^{\circ} \mathrm{C}$. It was also noted that the adsorption onto the chromium surface of abietic acid (at $25^{\circ} \mathrm{C}$ ) and triolein (at $25^{\circ} \mathrm{C}$ and $50^{\circ} \mathrm{C}$ ) reached a plateau before the $2 \mathrm{hr}$ adsorption period expired. For the other colloid types adsorption continued until the rinsing commenced. 
The rates of adsorption of the different colloid types onto the cellulose and chromium surfaces at $25^{\circ} \mathrm{C}$ and $50^{\circ} \mathrm{C}$, estimated from the slopes of the quasilinear region(s) in Figures 4 and 5, are compared in Figure 6 . Where there were two apparent linear regions, the different rates were estimated by considering each quasilinear region up to the point of inflexion. In general, the rates of adsorption onto cellulose surfaces for abietic acid and triolein colloids were much greater than the mixed model and wood extractive colloids, while the rate of adsorption of oleic acid was the lowest. Abietic acid was found to have the greatest rate of adsorption on the chromium surface, followed by triolein and mixed model colloids. Oleic acid and wood extractives exhibited the lowest rate of adsorption on the chromium surface.

Figure 7 compares the average maximum mass of each colloidal material deposited at $25^{\circ} \mathrm{C}$ and $50^{\circ} \mathrm{C}$ onto cellulose and chromium surfaces. Several key observations can be made from Figure 7 in regards to the effect of temperature, surface type and colloidal material being deposited. In the case of cellulose surface, more material was adsorbed at $50^{\circ} \mathrm{C}$ than at $25^{\circ} \mathrm{C}$ for all colloid materials. For the chromium surface, the average mass of colloidal material adsorbed was less at $50^{\circ} \mathrm{C}$ than at $25^{\circ} \mathrm{C}$, with the exception of the wood extractives and triolein colloidal type, though the difference for triolein were not statistically significant. Generally, the mass of colloidal material adsorbed on chromium at $25^{\circ} \mathrm{C}$ was higher than on cellulose at this temperature for all materials tested. Abietic acid and triolein were found to adsorb onto cellulose by as much as a factor of ten compared to other colloidal material onto cellulose at both temperatures. A significantly greater mass of wood extractives, mixed model compound and oleic acid were adsorbed onto chromium than onto cellulose at $50^{\circ} \mathrm{C}$. Overall the total mass of the colloidal materials adsorbed on the cellulose and chromium surfaces followed a similar trend, with abietic acid and triolein clearly demonstrating the greatest mass adsorption on each surface. The average mass adsorbed was slightly higher for the mixed model compounds, compared to both the wood extractives and oleic acid, with the latter demonstrating the lowest average mass adsorption on the cellulose and chromium surfaces (Figure 7). This is especially significant when the relatively low concentration of abietic acid in solution is taken into account. From an $86 \mathrm{mg} \mathrm{L}^{-1}$ solution of abietic acid, $12800 \mathrm{ng} \mathrm{cm}^{-2}$ was deposited on cellulose at $25^{\circ} \mathrm{C}$. In comparison to this only $240 \mathrm{ng} \mathrm{cm}^{-2}$ of oleic acid was deposited from an initial concentration of $217 \mathrm{mg} \mathrm{L}^{-1}$ and $11200 \mathrm{ng} \mathrm{cm}^{-2}$ of triolein was deposited from an initial concentration of $407 \mathrm{mg} \mathrm{L}^{-1}$ under the same conditions. 

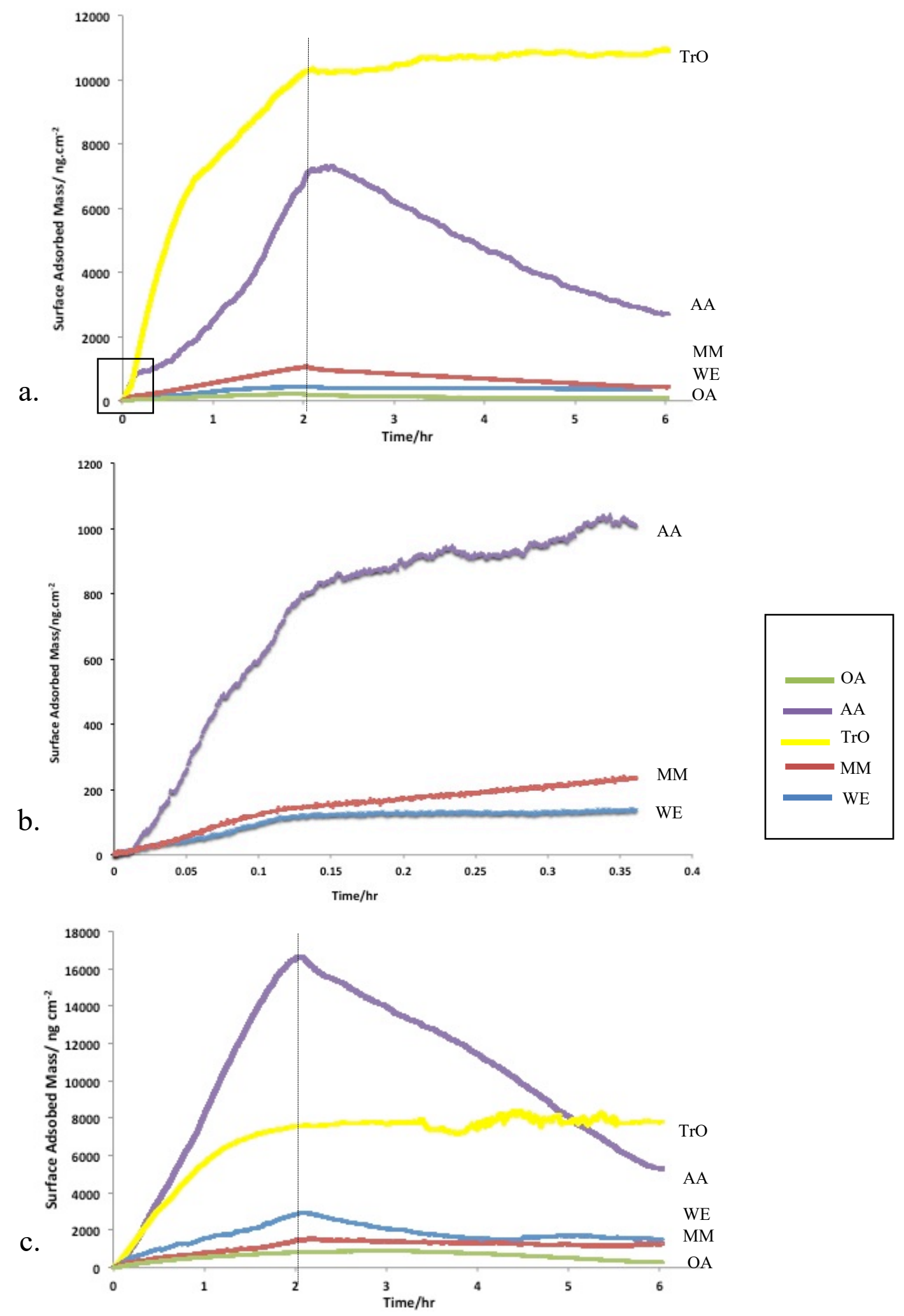

Figure 4 Representative plot of the time dependent adsorption of different colloidal materials on cellulose at $25^{\circ} \mathrm{C}$ (a) and $50^{\circ} \mathrm{C}(\mathrm{c})$. Graph (b) is a high-resolution plot of initial adsorption region of $A A, M M$ and WE on cellulose at $25^{\circ} \mathrm{C}$ (delineated by boxed area in (a)). Vertical line indicates the start of rinsing process. 
Figure 8 shows the final percentage of material desorbed from each surface when rinsed with $6 \mathrm{mM} \mathrm{NaCl}$ for an extended period. Triolein was found to adsorb very strongly to both the cellulose and chromium surfaces, as it did not desorb during the rinsing process. At $25^{\circ} \mathrm{C}$ oleic acid, abietic acid and mixed model colloids desorbed more readily from the cellulose surface than from the chromium surface. At $50^{\circ} \mathrm{C}$, there was no significant difference in the amount desorbed from cellulose or chromium surfaces for any of the colloidal materials except the wood extractive colloidal material. On a cellulose surface, almost double the amount of wood extractives was lost at $50^{\circ} \mathrm{C}$ compared to $25^{\circ} \mathrm{C}$, whereas on the chromium surface comparable amount of wood extractives was desorbed at both temperatures. However, unlike the adsorption processes, the desorption process was found to be very variable.

a.
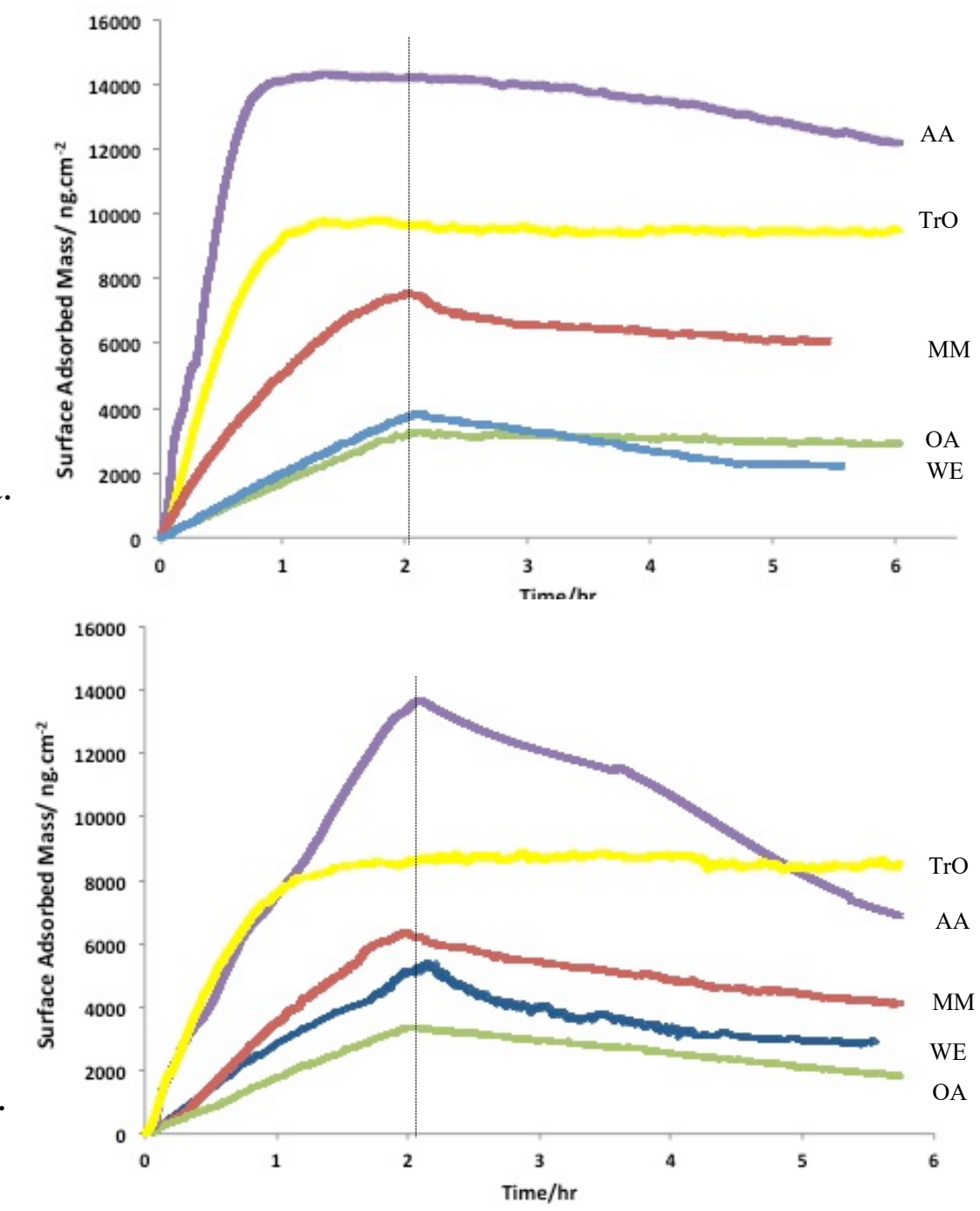

Figure 5 Representative plot of 'mass deposited per unit area against time' of different colloidal materials on chromium surface at $25^{\circ} \mathrm{C}$ (a) and at $50^{\circ} \mathrm{C}(\mathrm{b})$. Vertical line indicates the start of the rinsing process. 


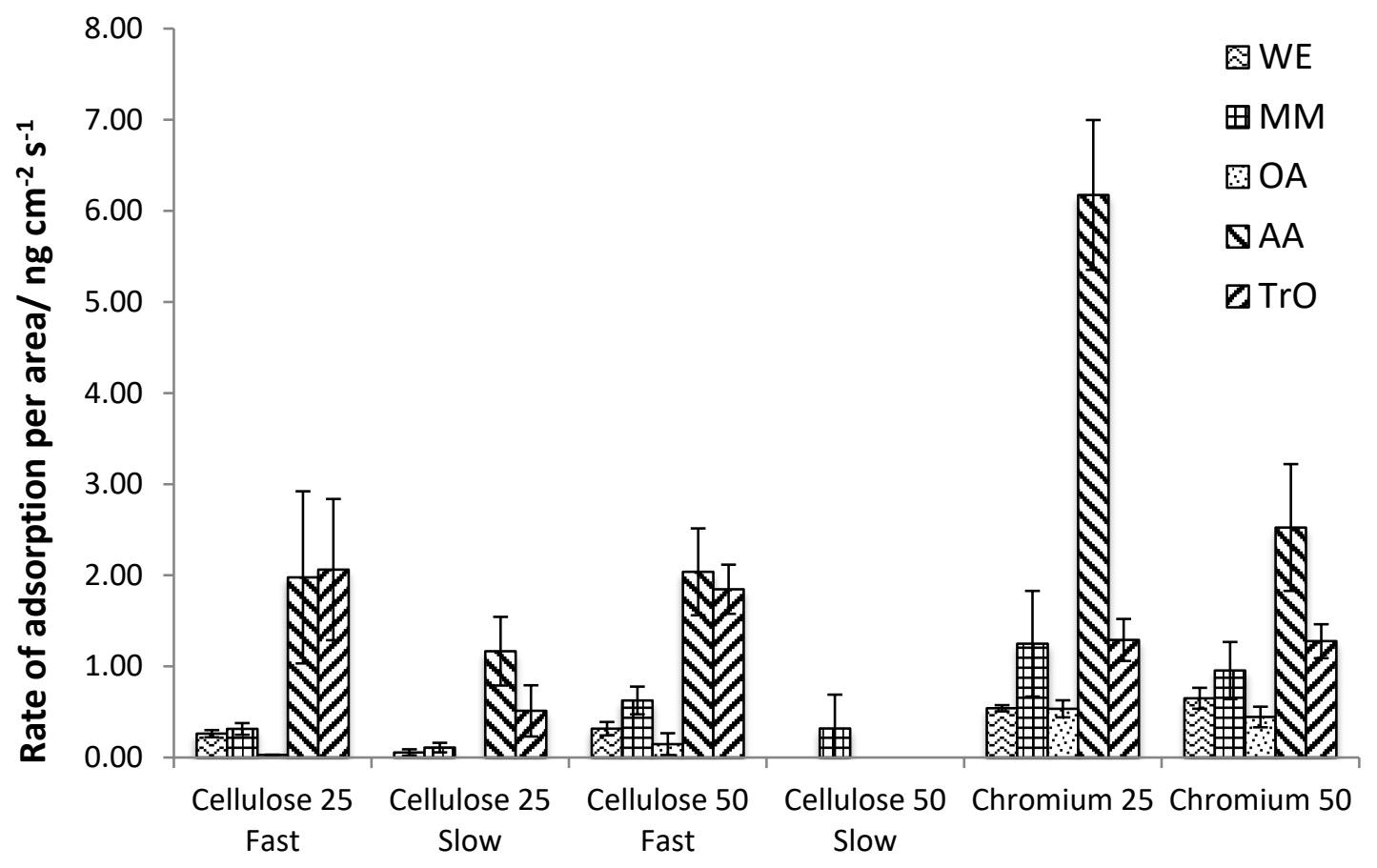

Figure 6 Rate of adsorption ( $\mathrm{ng} \mathrm{cm}^{-2} \mathrm{~s}^{-1}$ ) of different colloid types on cellulose and chromium surface at both $25^{\circ} \mathrm{C}$ and $50^{\circ} \mathrm{C}$. ('Fast' and 'Slow' denotes the different regions of rate on the adsorption process; $95 \%$ confidence interval $(\mathrm{Cl})$ as error bars)

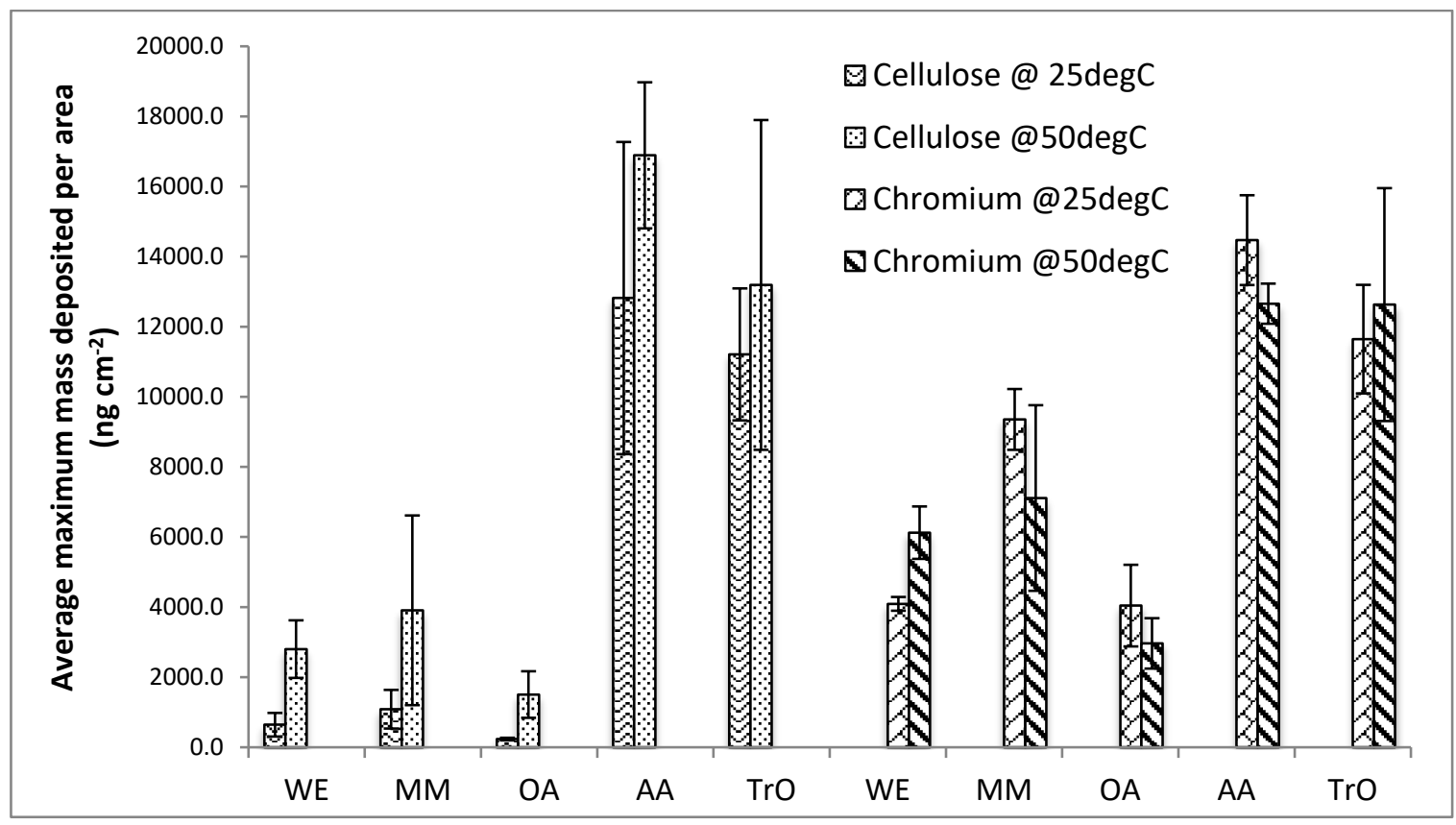

Figure 7 Average maximum mass deposited per unit area $\left(\mathrm{ng} \mathrm{cm}^{-2}\right)$ for different colloidal materials comparing two different temperatures $\left(25^{\circ} \mathrm{C}\right.$ and $\left.50^{\circ} \mathrm{C}\right)$ on two types of surfaces: cellulose and chromium surfaces. $(95 \%$ confidence interval $(\mathrm{Cl})$ as error bars.) 


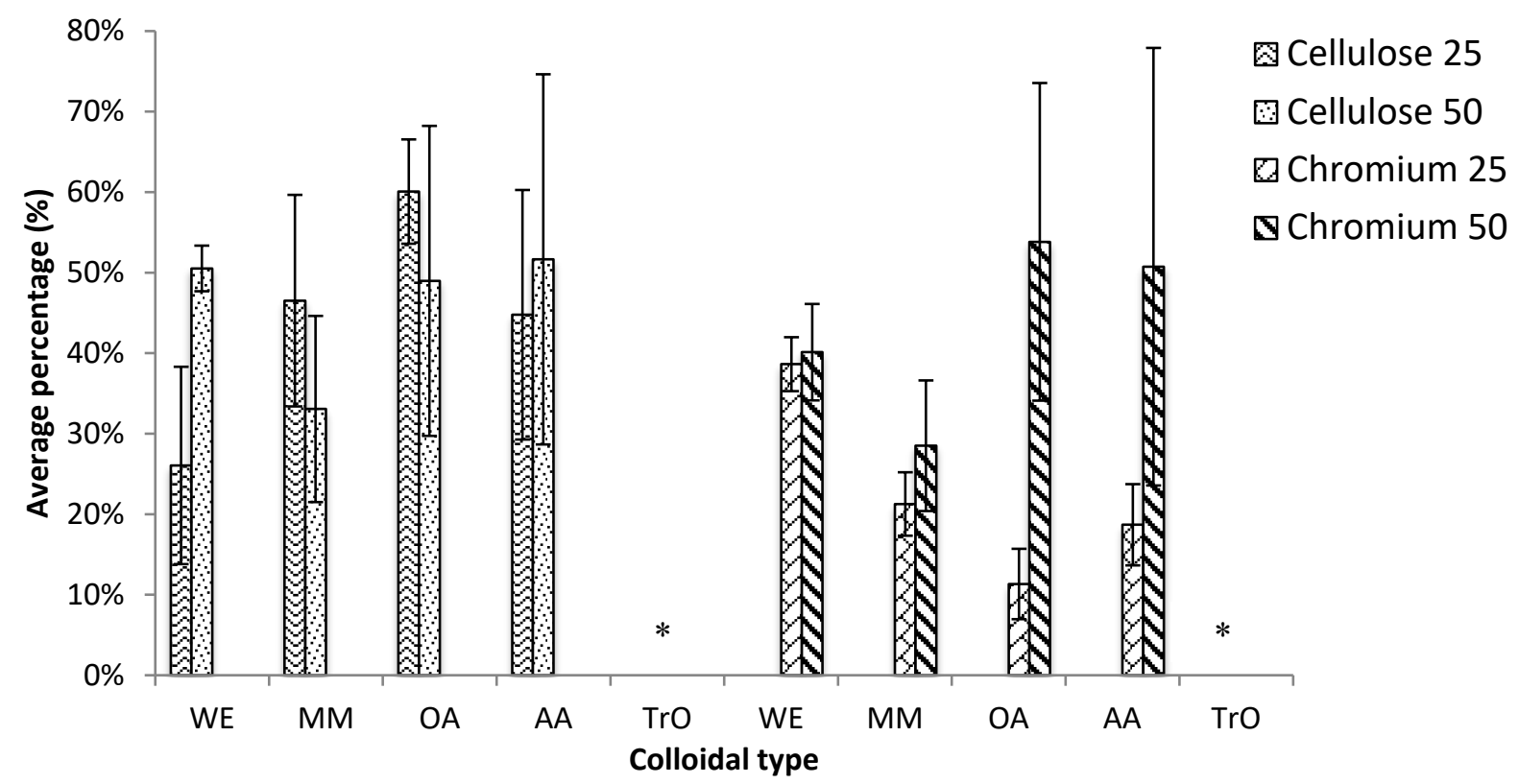

Figure 8 Average percentage of colloidal materials desorbed from cellulose and chromium surfaces at $25^{\circ} \mathrm{C}$ and $50^{\circ} \mathrm{C}$. Asterisks indicate no desorption of triolein (TrO). (95\% confidence interval ( $\mathrm{Cl}$ ) as error bars.)

\section{Discussion}

Microcrystalline cellulose-coated surfaces are rich in hydroxyl $(-\mathrm{OH})$ groups while chromium-coated surfaces in ambient conditions will form, at least in part, an oxide layer. In an aqueous environment, both these surfaces can be assumed to be weakly anionic in nature, as well as hydrophilic as shown by contact angle measurements (Table 2). ${ }^{29}$ The adsorption of oleic acid and abietic acid onto the surfaces is likely to be due to hydrogen bonding between the carboxyl groups on the fatty and resin acids and these weakly anionic surfaces. $\mathrm{pK}_{\mathrm{a}}$ values of oleic acid are reported to be 8.22 at $25^{\circ} \mathrm{C}$ and 8.29 at $50^{\circ} \mathrm{C}, 38$ while those of abietic acid are 7.26 at $25^{\circ} \mathrm{C}$ and 6.18 at $50^{\circ} \mathrm{C} .38$ The $\mathrm{pH}$ of the oleic acid and abietic acid colloidal solutions were measured to be around $\mathrm{pH} 5$ and $\mathrm{pH} 4$, respectively. At these pHs the carboxyl groups are predominantly protonated, which would support the postulation of hydrogen bonding between these functional groups.

Adsorption onto surfaces occurs when molecules achieve greater stability by precipitating or adsorbing to those surfaces than by remaining in solution. Adsorption of a solute from solution also involves competition between the solute and solvent for the adsorption sites. ${ }^{39}$ The adsorption process can result in either monolayer or multilayer coverage of materials on the surface as shown in Figure 9(a)-(f). Figure $9 \mathrm{a}$ is a schematic of simple monolayer 
coverage, Figure $9 \mathrm{~b}$ represents partial multilayer adsorption that could precede monolayer adsorption or remain as partial multilayer coverage, while Figure $9 \mathrm{c}$ is multilayer adsorption after complete monolayer coverage.

For molecules with charged or polar groups such as fatty acids and resin acids, Figure $9 \mathrm{~d}$ shows a monolayer of molecules that can either interact with the surface via a head to surface interaction or a tail to surface interaction. The orientation of the molecules on the surface is governed by the relationship between the surface and the solvent properties such as the hydrophobicity and the presence of active sites that could lead to specific adsorption. For an aqueous solution with fatty acids and resin acids adsorbing onto a hydrophilic surface (such as cellulose and chromium surfaces), the carboxylic acid head groups are more likely to interact with the active sites on the surface, while the hydrophobic tails will protrude into the aqueous solution. Such a single layer adsorption will not be stable in an aqueous solution as this results in hydrophobic tails residing in the aqueous solution. It is more likely that a second layer of molecules would quickly interact with the exposed hydrophobic tails via a tail-to-tail interaction thus forming a bilayer and leaving the polar head groups available to interact favourably with the solvent as shown in Figure 9e. This two-step adsorption leading to surface coverage followed by multilayer adsorption onto the surface layer can be used to explain the two different rates of adsorption observed with the colloids onto cellulose.

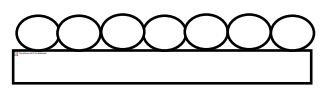

a

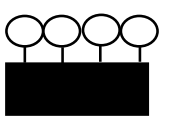

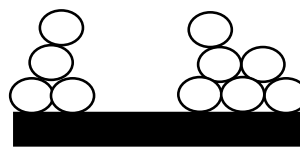

b

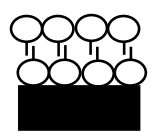

e

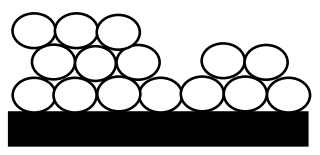

c

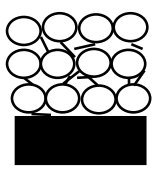

f.

d

Figure 9 Schematic diagram of possible adsorption process of material onto test surfaces: (a) Monolayer coverage; (b) Multilayer adsorption without full monolayer coverage achieved; (c) Multilayer adsorption after full monolayer coverage achieved; (d) tail-to-surface interaction or head-to-surface interaction of monolayer adsorption; (e) head-to-head and tail-to-tail multilayer adsorption; (f) non-specific multilayer adsorption. For $(d)-(f)$, the sphere represents oxygen containing groups, sticks represent hydrophobic portion.

Differences in the shape of the adsorption curves and also the mass of the absorbates onto the two different surfaces provide information about the dynamic adsorption process The adsorption onto the cellulose and chromium surfaces indicates formation of a multilayer, evident through the measured mass being far beyond that expected for a monolayer adsorption with the maximum amount adsorbed not reached prior to the rinsing step (with exceptions for adsorption of abietic acid and triolein on chromium at $25^{\circ} \mathrm{C}$ where saturation of surface occurred as indicated by the plateau region achieved in Figure 5a). However, the adsorption onto chromium shows 
only a single rate of adsorption that might indicate non-specific interactions between the surface and the adsorbate molecules as shown in Figure 9b and Figure 9c.

The two different adsorption rates observed with the abietic acid, triolein, mixed model compounds and the wood extractive colloids onto cellulose may be explained by a two-step adsorption in which a monolayer is formed on the surface followed by multilayer adsorption. The point of inflexion at which the rate changes should correspond to the point where monolayer coverage occurred. The theoretical mass adsorbed at monolayer coverage of each compound, $M_{a}$, can be determined using Eq 1 :

$$
M_{a}=M w /\left(S_{a} \times N\right)
$$

Where $S_{a}$ is the molecular area of the molecule adsorbed onto the surface, $M w$ is the molecular weight of the molecule and $\mathrm{N}$ is Avogadro's number. For abietic acid (Mw $=302 \mathrm{~g} \mathrm{~mol}^{-1}$ and assuming molecular cross sectional area of $1.4 \mathrm{~nm}^{2}$ obtained from molecular modelling using Gaussview), the calculated mass of an adsorbed monolayer can be estimated to be $35 \mathrm{ng} \mathrm{cm}^{-2}$, or $70 \mathrm{ng} \mathrm{cm}^{-2}$ if a bilayer occurs. This is significantly less than the $800 \mathrm{ng} \mathrm{cm}^{-2}$ observed at $25^{\circ} \mathrm{C}$ in Figure $4 \mathrm{~b}$ (at the point where second adsorption phase occurred). This clearly indicates that abietic acid is not adsorbing as individual molecules but as colloids. The concentration of abietic acid in solution is above the critical micelle concentration (CMC), determined previously to be $3 \mathrm{mg} \mathrm{L}^{-1} 40$ and so this finding is not unexpected. Likewise with adsorption of triolein $\left(\mathrm{Mw}=885 \mathrm{~g} \mathrm{~mol}^{-1}\right.$ and cross sectional area of 1.26 $\mathrm{nm}^{2}$ ) onto cellulose at $25^{\circ} \mathrm{C}$ (Figure 4a), the $7000 \mathrm{ng} \mathrm{cm}^{-2}$ adsorbed at the point of inflexion is significantly higher than the estimated mass adsorbed at molecular monolayer coverage of approximately $116 \mathrm{ng} \mathrm{cm}^{-2}$ again indicating that adsorption is not of individual molecules on the surface but colloids. As for oleic acid, molecules can either adsorb in a flat configuration on the surface or a close-packed configuration with the carboxylic acid interacting with the surface and the hydrocarbon chain orientated perpendicular from the surface. Applying the same calculations as before, the theoretical mass of an adsorbed monolayer of oleic acid molecules would be $41 \mathrm{ng} \mathrm{cm}$ 2 adopting a flat orientation (assuming surface area of $1.14 \mathrm{~nm}^{2}{ }^{41}$ ) and $234 \mathrm{ng} \mathrm{cm}^{-2}$ for a perpendicular orientation (assuming a surface area of $0.2 \mathrm{~nm}^{2}$ ). The estimated maximum mass of oleic acid adsorbed is about $230 \mathrm{ng} \mathrm{cm}^{-2}$ at $25^{\circ} \mathrm{C}$ and about $1400 \mathrm{ng} \mathrm{cm}^{-2}$ at the $50^{\circ} \mathrm{C}$. Therefore, at $25^{\circ} \mathrm{C}$ adsorption of oleic acid seems to just reach monolayer coverage if the molecules adsorb perpendicularly, however this orientation would be unfavourable as it leaves the hydrophobic tail of the oleic acid exposed to the aqueous environment. In addition, the concentration of oleic acid in solution was much greater than the CMC value of $4.5 \mathrm{mg} \mathrm{L}^{-1}$. Therefore, oleic acid would most likely also adsorb as colloids or admicelles ${ }^{42}$ onto the cellulose surface and spread to form a thin film on the surface, as shown in previous work. ${ }^{43,44}$

The adsorption behaviour of the colloids onto the chromium surface can be explained by multilayer adsorption. Colloids randomly adhere to the surface and interact with each other non-specifically, resulting in non-specific multilayer adsorption (Figure 9f). As the interactions between the surface and the colloids are non-specific, this mechanism is largely controlled by solubility limitations. In this case, the rate of deposition may be constant as fresh solution is being pumped over the sensor throughout the deposition process. The colloids adsorbed onto the 
surface are also stabilised by a cooperative interaction with other colloids already on the surface. This means that multilayer formation occurs before a monolayer surface coverage is achieved. The adsorption of abietic acid and triolein onto the chromium surface (at $25^{\circ} \mathrm{C}$ ) is clearly not of molecular monolayer coverage based on the mass adsorbed and the calculated theoretical masses at monolayer coverage. The observed plateau in the adsorption may be due to the saturation at the adsorption surface, which then prevents further interaction between surface colloids and other molecules or colloids in solution.

Based on Figure 6 and Figure 7, abietic acid adsorbed more rapidly and to a greater extent than oleic acid. This suggests that abietic acid has a stronger interaction with both surfaces than oleic acid. Maher et al. has shown that, as a single component, abietic acid has a stronger tendency to deposit onto fibre or non-fibre surfaces than oleic acid or triolein. ${ }^{45}$ However, the observation of triolein remaining in the dissolved colloidal phase in the study by Maher et al. contradicts the observation made in this study where triolein deposits onto surfaces as quickly as does abietic acid. The difference in behaviour could be explained by the differences in the surfaces as Maher used mechanical pulp fibres which would contain hemicelluloses, cellulose and lignin; whereas the non-fibre surfaces were plastics.

The mass of abietic acid adsorbed onto cellulose, at $25^{\circ} \mathrm{C}$, was less than the mass of that adsorbed onto the chromium surface at this temperature (Figure 7). During the desorption process, twice the amount of abietic acid desorbed from the cellulose surface than from the chromium surface (Figure 8). This indicates that the abietic acid was adsorbed more strongly and with a more stable arrangement on the chromium surface, an observation in line with the previously mentioned phenomena where abietic acid preferentially deposits and strongly adhered onto chromium surfaces in the papermaking and printing processes. Even though both cellulose and chromium surfaces are hydrophilic in nature contact angle measurements of these two surfaces showed that the chromium surface is more hydrophilic than the cellulose surface. This may explain the stronger interaction of polar aggregates such as abietic acid with chromium than with a cellulose surface.

The adsorption of triolein (TrO), representative of triglycerides, is very different to that from the adsorption of oleic acid or abietic acid. The lowest energy molecule conformation of triolein is shown in Figure 1(c), where all the hydrophobic tails are directed into the surrounding aqueous solution. ${ }^{46}$ Dispersion forces can be assumed to be very strong between triolein molecules as compared to oleic acid and abietic acid molecules because triolein has a greater surface area of interaction. More importantly, the interaction between triolein molecules and a hydrophobic surface is stronger than its interaction with water. This can be extended to strong interactions between triolein molecules due to the poor solute-solvent interaction, leading to negligible or no desorption of triolein over four hours of rinsing after deposition (Figure 8).

Temperature has been shown to have an effect on the properties of wood extractives. ${ }^{4}$ Since, the operating temperature in the papermaking process is around $60^{\circ} \mathrm{C}$, it is necessary to investigate the effect of increasing the 
temperature in the adsorption experiments. Increasing the temperature from $25^{\circ} \mathrm{C}$ to $50^{\circ} \mathrm{C}$ was found to have a greater effect on adsorption onto cellulose surfaces than onto chromium surfaces. McLean et al. suggested that solubility of each colloidal type increased with increasing temperature ${ }^{47}$ while it is also know that viscosity of these solutions decreases at higher temperature. ${ }^{4}$ This may infer that the colloidal solution becomes more fluid-like, increasing the probability of both the attraction of the molecule to the surface and the attraction between molecules. Other than changing viscosity of the colloids, increasing the temperature is believed to lead to more active sites being exposed on the cellulose surface. ${ }^{48}$ When all of these contributing factors are taken into account it would be expected that the deposition of colloids onto the cellulose surface would be greater at a higher temperature, as was found to be the case (Figure 7). However, on the chromium surface where much of the same logic should apply, deposition was about the same at an increased temperature (Figure 7). This would indicate that the increased adsorption on cellulose at higher temperature was largely due to the increase in the active sites (which may have been previously tightly bound when at low temperature) being exposed on the cellulose surface at increased temperature, which caused swelling of the structure, allowing an increase in the mobility of the cellulose chains. ${ }^{48}$

In recent years, a three-layered model for wood extractive colloid structure was proposed by Lee et al. ${ }^{49}$ where the triolein occupies the hydrophobic core, resin acids on the outermost shell and the fatty acid layer exists as a mobile layer between the outer layer and inner core (Figure 10). Interactions between different components in mixed model and wood extractive colloids have been found to stabilise the colloids to a greater extent than colloids composed of the single components. ${ }^{50,51}$ In addition to these interactions between the primary components of the colloid itself, it is known that other components in wood extractives such as wood carbohydrates and lignin components may help stabilise colloids in solution.

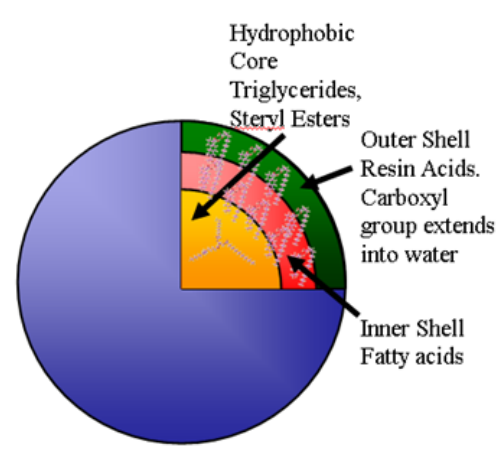

Figure 10 Schematic representation of wood extractive colloid model with triglycerides in the core and the fatty acids and resin acids in the outer layer.

Our results for both the mixed-model and wood extractive colloidal materials demonstrate significantly lower adsorption to both chromium and cellulose substrates at $25^{\circ} \mathrm{C}$ and $50^{\circ} \mathrm{C}$, compared to single component abietic acid and triolein colloids (Figure 7). Additionally, the rates of adsorption of mixed model and wood extractives were lower than for triolein and abietic acid on cellulose at both $25^{\circ} \mathrm{C}$ and $50^{\circ} \mathrm{C}$ (with the exception of the second adsorption phase at $50^{\circ} \mathrm{C}$ where a two phase adsorption was only demonstrated for the mixed model colloid). On 
the other hand the rate of adsorption of abietic acid on chromium was significantly greater than both the mixed model and wood extractives colloids, while the rate for triolein adsorption on this surface was significantly greater than wood extractives, but comparable to the mixed model colloid. The oleic acid colloid exhibited generally comparable or smaller values for both the total mass of adsorption and the adsorption rate than both the mixed component colloids (Figure 6 - Figure 7).

There is clear indication of stabilisation effects in the formation of colloids with a mixture of abietic acid, oleic acid and triolein (mixed model compound colloids), even though the effects are not as significant as with wood extractives due to the lack of other components that may exist in genuine wood extractive sample. However despite having different ratios of oleic acid and abietic acid within mixed model compound colloids and wood extractives, the amount adsorbed and desorbed onto microcrystalline cellulose and chromium surfaces were quite similar (Figure 7 and Figure 8).

\section{Conclusion}

QCM-D has been shown to be a useful technique for studying the adsorption of different colloidal materials onto both cellulose and chromium surfaces. On both model surfaces, the greatest adsorption occurred for abietic acid and triolein, pointing to these compounds being the least stable in solution and/or having the greatest interaction with the surfaces. In particular, triolein was found to be tightly bound to the test surface as no desorption occurred with extended rinsing. Comparatively, less deposition for oleic acid, mixed model compounds and wood extractives occurred, indicating that these colloids are more stable in solution and have a lower interaction with the cellulose and chromium surfaces.

Differences in the shape of the adsorption curves between the two surfaces were evident. Adsorption onto cellulose appeared to be a two-phase process in which it is proposed that surface coverage of the cellulose occurs prior to further multilayer deposition of colloids interacting with each other. The layers of colloids aggregates on the surface readily desorb with rinsing of the surface. On the chromium surface, it is proposed that multilayer adsorption occurs slightly differently with colloids interacting with each other and cooperatively stabilising the interaction with the surface thus building up layers prior to achieving full surface coverage. Less of the material is removed in the rinsing stage compared with the cellulose surface indicating that the aggregate interactions are slightly stronger when formed in this way on the chromium surface.

From the experimental results, increasing temperature had a greater effect on the deposition of all colloidal types onto a cellulose surface than onto a chromium surface. Deposition at both low $\left(25^{\circ} \mathrm{C}\right)$ and higher $\left(50^{\circ} \mathrm{C}\right)$ temperatures were greater on chromium surfaces except more abietic acid was deposited onto cellulose-coated surface at $50^{\circ} \mathrm{C}$ and deposition of triolein colloidal materials were quite similar for both surfaces at $50^{\circ} \mathrm{C}$. Increasing the temperature is believed to have an effect on the properties of the colloidal materials as well as changes to surface properties of the cellulose surface that leads to greater deposition on the cellulose surface. However, as 
the surface properties of the chromium surface do not change with increased temperature, the changes to deposition can only be attributed to changes in properties of colloidal materials and not to changes of chromium surface properties.

\section{Acknowledgements}

The first author acknowledges the financial assistance of Norske Skog Paper Mills Australia Ltd for a postgraduate scholarship. Financial support for this project was provided via an ARC Linkage grant (LP120200241). Gratitude is extended to the ARC Centre of Excellence Electromaterials Science, Intelligent Polymer Research Institute for the use of facilities and instrumentation.

\section{References}

1. Featherstone, A.; Viney, D.; Mosbye, J.; Richardson, D. In Deposit control: Does adsorption of colloidal extractives to bentonite affect the dissolution of resin acids?, 60th Appita Annual Conference, 2006; Appita, Ed. 2006; pp 417-420.

2. Wallqvist, V.; Claesson, P. M.; Swerin, A.; Schoelkopf, J.; Gane, P. A. C., Interaction forces between talc and pitch probed by atomic force microscopy. Langmuir 2007, 23, 4248-4256.

3. Mosbye, J. Colloidal wood resin: Analyses and interactions. PhD thesis, NTNU Trondheim Norwegian University of Science and Technology, Trondheim, 2003.

4. Qin, M.; Hannuksela, T.; Holmbom, B., Physico-chemical characterisation of TMP resin and related model mixtures. Colloids and Surfaces A: Physicochemical and Engineering Aspects 2003, 221, 243-254.

5. Sundberg, A.; Strand, A.; Vahasalo, L.; Holmbom, B., Phase distribution of resin and fatty acids in colloidal wood pitch emulsions at different pH-levels. Journal of Dispersion Science and Technology 2009, 30, 912-919.

6. Vercoe, D.; Stack, K.; Blackman, A.; Richardson, D. In Interaction of pitch components at a molecular level, WPP 2003 Chemical Technology of Wood, Pulp and Paper International Conference, Bratislava, Slovak Republic, September 17.-19. 2003, 2003; Bratislava, Slovak Republic, 2003; pp 127-133.

7. Opedal, M. T.; Stenius, P.; Johansson, L., Review: Colloidal stability and removal of extractives from process water in thermomechanical pulping. Nordic Pulp and Paper Research Journal 2011, 26, 248-257.

8. $\quad$ Kallio, T.; Lindfors, J.; Laine, J.; Stenius, P., Spreading and adhesion of lipophilic extractives on surfaces in paper machines. Nordic Pulp and Paper Research Journal 2008, 23, 108-119.

9. $\quad$ Porubská, J.; Alince, B.; van de Ven, T. G. M., Homo- and heteroflocculation of papermaking fines and fillers. Colloids and Surfaces A: Physicochemical and Engineering Aspects 2002, 210, 223-230.

10. Lee, R.; Stack, K.; Richardson, D.; Lewis, T. W.; Garnier, G., Study of pitch colloidal stability using a photometric dispersion analyser. Appita Journal 2010, 63, 387-406.

11. Lee, R.; Garnier, G.; Lewis, T.; Richardson, D.; Van De Ven, T. G. M.; Stack, K., Pitch deposition at the solid-liquid interface: Effect of surface hydrophobicity/hydrophilicity and cation specificity. Colloids and Surfaces A: Physicochemical and Engineering Aspects 2011, 388, 84-90.

12. Murray, G.; Stack, K.; McLean, D. S.; Shen, W.; Garnier, G., Dynamics of colloidal pitch adsorption at the solid-liquid interface by surface plasmon resonance. Colloids and Surfaces A: Physicochemical and Engineering Aspects 2009, 341, 127-133.

13. Vahasalo, L.; Degerth, R.; Holmbom, B., The use of flow cytometry in wet end research. Paper Technology 2003, 44, 45-49.

14. Saarimaa, V. V., Lari; Sundberg, Anna; Pranovich, Andrey; Holmbom, Bjarne; Svedman, Mikael; Orsa, Folke., Influence of pectic acids on aggregation and deposition of colloidal pitch. Nordic Pulp \& Paper Research Journal 2006, 21, 613-619.

15. McLean, D. S.; Stack, K. R.; Richardson, D. E.; Haddad, P. R. In Wood pitch fixative selection by laser particle size analysis, $60^{\text {th }}$ Appita Annual General Conference Proceedings, Melbourne, Australia, 3-5 April, 2006; Appita: Melbourne, Australia, 2006; pp 413-416. 
16. Henry, C., Product Review: Measuring the masses: Quartz crystal microbalances. Analytical Chemistry $1996,68,625 \mathrm{~A}-628 \mathrm{~A}$.

17. Schumacher, R., The quartz microbalance - A novel approach to the in-situ investigation of intergacial phenomena at the solid/liquid junction. Angewandte Chemie - International Edition in English 1990, 29, 329-343.

18. Marx, K. A., Quartz Crystal Microbalance: A Useful Tool for Studying Thin Polymer Films and Complex Biomolecular Systems at the Solution-Surface Interface. Biomacromolecules 2003, 4, 1099-1120.

19. Sauerbrey, G., VERWENDUNG VON SCHWINGQUARZEN ZUR WAGUNG DUNNER SCHICHTEN UND ZUR MIKROWAGUNG. Zeitschrift Fur Physik 1959, 155, 206-222.

20. King, W. H., Piezoelectric Sorption Detector. Analytical Chemistry 1964, 36, 1735-1739.

21. Bruckenstein, S.; Shay, M., An in situ weighing study of the mechanism for the formation of the adsorbed oxygen monolayer at a gold electrode. Journal of Electroanalytical Chemistry and Interfacial Electrochemistry 1985, 188, 131-136.

22. Benje, M.; Eiermann, M.; Pittermann, U.; Weil, K. G., An Improved Quartz Microbalance. Applications to the Electrocrystallization and -dissolution of Nickel. Berichte der Bunsengesellschaft für physikalische Chemie 1986, 90, 435-439.

23. Thompson, M.; Arthur, C. L.; Dhaliwal, G. K., Liquid-phase piezoelectric and acoustic transmission studies of interfacial immunochemistry. Analytical Chemistry 1986, 58, 1206-1209.

24. Nivens, D. E.; Chambers, J. Q.; Anderson, T. R.; White, D. C., Long-term, on-line monitoring of microbial biofilms using a quartz crystal microbalance. Analytical Chemistry 1993, 65, 65-69.

25. Gryte, D. M.; Ward, M. D.; Hu, W. S., Real-time measurement of anchorage-dependent cell adhesion using a quartz crystal microbalance. Biotechnology Progress 1993, 9, 105-108.

26. Rodahl, M.; Höök, F.; Krozer, A.; Brzezinski, P.; Kasemo, B., Quartz crystal microbalance setup for frequency and $Q$ - factor measurements in gaseous and liquid environments. Review of Scientific Instruments 1995, 66, 3924-3930.

27. Rodahl, M.; Höök, F.; Kasemo, B., QCM Operation in Liquids: An Explanation of Measured Variations in Frequency and Q Factor with Liquid Conductivity. Analytical Chemistry 1996, 68, 2219-2227.

28. Rodahl, M.; Kasemo, B., A simple setup to simultaneously measure the resonant frequency and the absolute dissipation factor of a quartz crystal microbalance. Review of Scientific Instruments 1996, 67, 3238-3241.

29. Tammelin, T.; Johnsen, I. A.; Osterberg, M.; Stenius, P.; Laine, J., Adsorption of colloidal extractives and dissolved hemicelluloses on thermomechanical pulp fiber components studied by QCM-D. Nordic Pulp \& Paper Research Journal 2007, 22, 93-101.

30. Kou, J.; Tao, D.; Xu, G., Fatty acid collectors for phosphate flotation and their adsorption behavior using QCM-D. International Journal of Mineral Processing 2010, 95, 1-9.

31. Kou, J.; Tao, D.; Sun, T.; Xu, G., Application of the quartz crystal microbalance with dissipation method to a study of oleate adsorption onto a hydroxyapatite surface. Minerals \& Metallurgical Processing 2012, 29, 4755 .

32. Stack, K.; Lee, R.; Rao, R.; Richardson, D.; Garnier, G.; Lewis, T. W., Effect of pitch preparation on its colloidal properties and deposition behaviour. Appita Journal 2009, 353-358.

33. Mohamad Haafiz, M. K.; Eichhorn, S. J.; Hassan, A.; Jawaid, M., Isolation and characterization of microcrystalline cellulose from oil palm biomass residue. Carbohydrate Polymers 2013, 93, 628-634.

34. Abdelsalam, M. E.; Bartlett, P. N.; Kelf, T.; Baumberg, J., Wetting of regularly structured gold surfaces. Langmuir 2005, 21, 1753-1757.

35. Steele, D. F.; Moreton, R. C.; Staniforth, J.; Young, P.; Tobyn, M.; Edge, S., Surface energy of microcrystalline cellulose determined by capillary intrusion and inverse gas chromatography. The American Association of Pharmaceutical Scientists (AAPS) Journal 2008, 10, 494-503.

36. Kuze, E.; Teramoto, T.; Yukimura, K.; Maruyama, T., Contact angle of water on chromium nitride thin film prepared on three-dimensional materials by chromium plasma-based ion implantation. Surface and Coatings Technology 2002, 158, 577-581.

37. Jodar-Reyes, $\quad$ A. $\quad$ B.; Mendez-Vilas, A.; Gonzalez-Martin, $\quad M \quad$ L., Experimental contribution to the understanding of wetting of solid surfaces at the meso-- and nano-

scale using dynamic AFM. Modern Research and Educational Topics in Microscopy 2007, 2, 500-512.

38. McLean, D. S.; Vercoe, D.; Stack, K. R.; Richardson, D., The colloidal $p K_{a}$ of lipophilic extractives commonly found in Pinus radiata. Appita Journal 2005, 58, 362-366.

39. Shaw, D. J., Chapter 8 Colloid stability. In Introduction to Colloid and Surface Chemistry, 4th ed.; Butterworth-Heinemann: Oxford, 1992; pp 211-243. 
40. Vercoe, D. Study of the Interactions Leading to Wood Resin Deposition. PhD, University of Tasmania, Hobart, 2004.

41. Rogan, K. R., Adsorption of oleic acid and triolein onto various minerals and surface-treated minerals Colloid and Polymer Science 1994, 272, 82-98.

42. Shaobin, W.; Yuelian, P., Natural zeolites as effective adsorbents in water and wastewater treatment. Chemical Engineering Journal 2010, 156, 11-24.

43. Fardim, P.; Gustafsson, J.; von Schoultz, S.; Peltonen, J.; Holmbom, B., Extractives on fiber surfaces investigated by XPS, ToF-SIMS and AFM. Colloids and Surfaces A: Physicochemical and Engineering Aspects 2005, 255, 91-103.

44. Koljonen, K.; Österberg, M.; Kleen, M.; Fuhrmann, A.; Stenius, P., Precipitation of lignin and extractives on kraft pulp: effect on surface chemistry, surface morphology and paper strength. Cellulose 2004, 11, 209-224.

45. Maher, L.; Stack.K; McLean, D.; Richardson, D., Adsorption behaviour of cationic fixatives and their effect on pitch deposition. Appita Journal 2007, 60, 112-119, 128.

46. Vercoe, D.; Stack, K.; Blackman, A.; Richardson, D., A multicomponent insight into the interactions leading to wood pitch deposition. Appita Journal 2005, 58, 208-213.

47. McLean, D. S.; Stack, K. R.; Richardson, D. E., The effect of wood extractives composition, pH and temperature on pitch deposition. Appita Journal 2005, 58, 52-55, 76.

48. Froix, M. F.; Goedde, A. O., The effect of temperature on the cellulose/water interaction from NMR relaxation times. Macromolecules 1976, 9, 428-430.

49. Lee, R.; Stack, K.; Lewis, T.; Garnier, G.; Richardson, D.; Ottaviani, M. F.; Jockusch, S.; Turro, N. J., Structure of wood extract colloids and effect of $\mathrm{CaCl} \square$ on the molecular mobility. Nordic Pulp and Paper Research Journal 2012, 27, 639-646.

50. Ödberg, L.; Forsberg, S.; McBride, G.; Persson, M.; Stenius, P.; Ström, G., Surfactant behavior of wood resin components. Part 2. Solubilization in micelles of rosin and fatty acids. Svensk Papperstidning 1985, 88, R118R125.

51. Palonen, H.; Stenius, P.; Ström, G., Surfactant behavior of wood resin components. The solubility of rosin and fatty acid soaps in water and in salt solutions. Svensk Papperstidning 1982, 85, R93-R99. 